\title{
Bax Inactivation in Lurcher Mutants Rescues Cerebellar Granule Cells But Not Purkinje Cells or Inferior Olivary Neurons
}

\author{
Fekrije Selimi, ${ }^{1}$ Michael W. Vogel, ${ }^{2}$ and Jean Mariani ${ }^{1}$ \\ 1 Laboratoire Développement et Vieillissement du Système Nerveux, Institut des Neurosciences, Centre National de la \\ Recherche Scientifique, Unité Mixte de Recherche 7624, Université Pierre et Marie Curie, 75005 Paris, France, and \\ 2Maryland Psychiatric Research Center, University of Maryland Medical School, Baltimore, Maryland 21228
}

\begin{abstract}
Lurcher is a gain-of-function mutation in the $\delta 2$ glutamate receptor gene (Grid2) that turns the receptor into a leaky ion channel. The expression of the Lurcher gene in heterozygous (Grid2 ${ }^{L C /+}$ ) mutants induces the death of almost all Purkinje cells starting from the second postnatal week. Ninety percent of the granule cells and $60-75 \%$ of the inferior olivary neurons die because of the loss of their target neurons, the Purkinje cells. The apoptotic nature of the neurodegeneration has been demonstrated previously by the presence of activated caspase-3 and DNA fragmentation. Bax, a pro-apoptotic gene of the Bcl-2 family, has been shown to be involved in developmental neuronal death. To study the role of Bax in Grid2 $2^{L C /+}$ neurodegeneration, double mutants with Grid2 $2^{L C /+}$ mice and Bax knock-out mice (Bax-/-) were generated. Bax deletion had no effect on the death of Purkinje
\end{abstract}

cells and inferior olivary neurons, although a temporary rescue of some Purkinje cells could be detected in P15 Grid $2^{\mathrm{Lcl}+}$;Bax-/animals. From postnatal day 15 (P15) to P60, the number of granule cells in Grid2 $2^{L C /+} ; \mathrm{Bax}-/-$ mice did not significantly change and was significantly increased compared with the number found in Grid2 $2^{\mathrm{LCl+}} ; \mathrm{Bax}+/+$ mice. Granule cell number in P60 Grid2 ${ }^{L C /+} ; \mathrm{Bax}-/-$ mice corresponded to $70 \%$ of the number found in wild-type mice. Our results show that Bax inactivation in Grid2 ${ }^{L C /+}$ mice does not rescue intrinsic Purkinje cell death or the target-related cell death of olivary neurons, but Bax inactivation does inhibit persistently target-related cell death in cerebellar granule cells.

Key words: Lurcher; Bax; Purkinje cell; granule cell; inferior olive; neuronal death
The heterozygous Lurcher mutant $\left(\mathrm{Grid} 2^{L c /+}\right)$ has been studied extensively as a model for understanding the mechanisms of cell autonomous and target-related neuronal cell degeneration. In the Grid2 ${ }^{L c /+}$ mutant, almost all cerebellar Purkinje cells (PCs), 60$75 \%$ of the olivary neurons, and $90 \%$ of the granule cells degenerate starting after the first week of postnatal development (Phillips, 1960; Caddy and Biscoe, 1979). Studies of Grid2 ${ }^{L c /+} \leftrightarrow$ wild type chimeras established that Grid $2^{L c /+}$ Purkinje cell death is cell autonomous, whereas granule cell and olivary neuron cell death is secondary to the loss of their primary target, the Purkinje cells (Wetts and Herrup, 1982a,b). More recent molecular studies have established that the Lurcher mutation is caused by a base pair change in the $\delta 2$ glutamate receptor gene (Grid2) that greatly increases its conductance (Zuo et al., 1997). Given the nature of Grid2 gene mutation, it appears likely that $G r i d 2^{L c /+}$ Purkinje cells are dying by an excitotoxic mechanism. The molecular mechanisms of Grid $2^{L c /+}$ Purkinje cell death have not yet been determined. However, the presence of activated caspase- 3 and terminal deoxynucleotidyl transferase-mediated dUTP nick end labeling (TUNEL) in dying Purkinje cells, granule cells, and olivary neurons of Lurcher mice suggest that these neuronal deaths are apoptotic (Norman et al., 1995; Wullner et al., 1995; Selimi et al., 2000).

The purpose of this study was to determine the effects of deleting the pro-apoptotic gene Bax on Purkinje, granule, and olivary neuron survival in the Grid2 $2^{L c /+}$ mutant. We have shown previously

\footnotetext{
Received Nov. 29, 1999; revised March 28, 2000; accepted May 1, 2000.

This work was supported by European Community Biotech Grant BIO4C960774 (to J.M.) and National Institutes of Health Grant NS34309 (to M.W.V.). We thank P. Bouquet for her help with the histology, P. Nguyen from the Centre de Traitement et de Productíon d'Images for his help with digital figures, and F. Frédéric for her help with statistical analysis. Bax knock-out mice were kindly provided by Dr. S. Korsmeyer.

Correspondence should be addressed to Dr. Jean Mariani, Laboratoire Développement et Vieillissement du Système Nerveux, Institut des Neurosciences, Centre National de la Recherche Scientifique, Unité Mixte de Recherche 7624, Université Pierre et Marie Curie, 9 Quai St. Bernard, 75005 Paris, France. E-mail: Jean. Mariani@snv.jussieu.fr.

Copyright (C) 2000 Society for Neuroscience $0270-6474 / 00 / 205339-07 \$ 15.00 / 0$
}

that Grid $2^{L c /+}$ Purkinje cell death can be delayed and Grid $2^{L c /+}$ olivary neurons rescued by the overexpression of the anti-apoptotic gene $b c l-2$ (Zanjani et al., 1998a,b). The $b c l-2$ proto-oncogene encodes an integral membrane protein that inhibits apoptosis in many cell types, although its mechanism of action is still not completely understood (Adams and Cory, 1998). One important function of BCL-2 may be to counteract the pro-apoptotic effects of BAX (Gross et al., 1999). BCL-2 will bind to BAX, and cell death may be regulated by the ratio of BCL-2 to BAX (Oltvai et al., 1993). BAX is involved in developmental cell death because deletion of the $B a x$ gene reduces the incidence of naturally occurring neuronal death in vivo (White et al., 1998). Bax-/- neurons also survive trophic factor withdrawal in vitro or after in vivo axotomy (Deckwerth et al., 1996). The results of our study show that deletion of Bax in the Grid $2^{L C /+}$ mutant does not prevent the excitotoxic Purkinje cell death or the target-related olivary neuron death. However, Bax inactivation increases survival of granule cells, supporting a role for BAX in target-related cell death of granule cells. The dichotomy between granule cell rescue and olivary neuron death in the Grid2 ${ }^{L c /+} ; B a x-/-$ mutant suggests that different cell death mechanisms are at work, even in two neuronal populations that are dying because of the loss of the same target.

\section{MATERIALS AND METHODS}

Animals and genotyping. Grid $2^{L C /+} ; B a x-/-$ double mutants were generated by heterozygous matings of Grid2 $2^{L C /+}$ and Bax $+/-$ mutants in the animal facilities at the Université Pierre et Marie Curie. Grid2 ${ }^{\mathrm{Lc} /+}$ mutants (B6AKR strain) are maintained in a colony at the Université Pierre et Marie Curie, and heterozygous Bax $+1-$ mutants were obtained from Dr. Stanley Korsmeyer (Harvard Medical School, Boston, MA). The Bax-/knock-out mutant was generated by homologous recombination to delete exons 2 through 5 to make a nonfunctional protein (C57BL6/RW-4 strain) (Knudson et al., 1995). In the mating scheme to generate homozygous and heterozygous double mutants, Grid $2^{L c /+}$ males were first mated with Bax heterozygous knock-out females. The Grid2 ${ }^{L c /+} ; B a x+/-$ animals were then intercrossed. Litters were killed at postnatal day 15 (P15), P30, and P60, using the guidelines established by Le Comité National d'Éthique pour les Sciences de la Vie et de la Santé. The Grid2 ${ }^{L c /+} ; B a x+/-$ and Grid2 $^{L c /+} ;$ Bax $+/+$ control animals used in this study were obtained in the same litters as the double mutants.

Genotyping for Bax was performed by PCR using a set of three primers: 

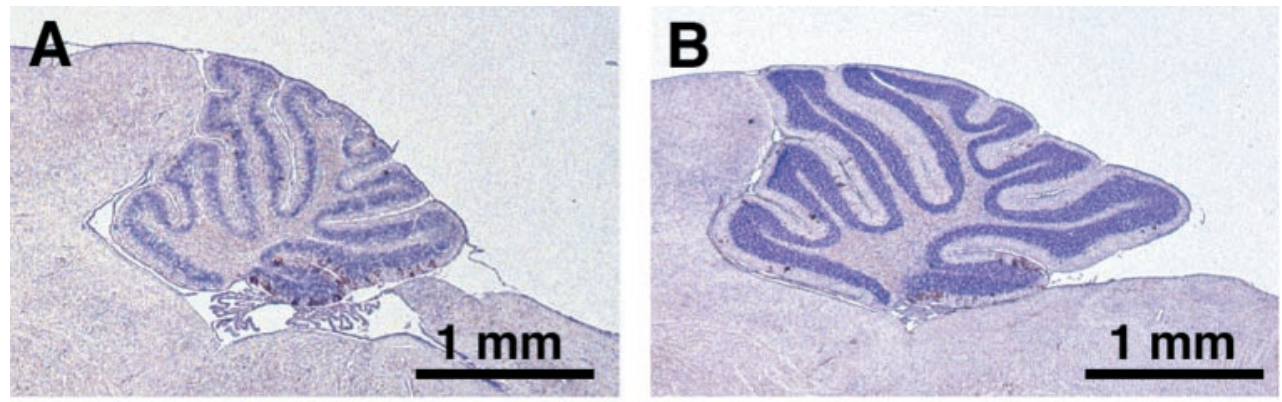

Figure 1. Bax inactivation in Lurcher mice rescues granule cells but not Purkinje cells. Midsagittal cerebellar sections $(10-\mu \mathrm{m}$ thick) of 1-month-old animals were immunostained using an anti-calbindin antibody specifically labeling Purkinje cells and counterstained with cresyl violet-thionin. In $\operatorname{Grid}^{L C /+} ;$ Bax $+/+$ control mice $(A)$, a massive loss of Purkinje cells and granule cells is detected. Purkinje cells have degenerated as well in Grid2 $2^{L c /+} ; \mathrm{Bax}-/-$ double mutant mice $(B)$, but an increased number of cresyl violet-stained granule cells are observed. Purkinje cells are atrophic with thicker dendrites in both Grid2 ${ }^{L c /+} ; \mathrm{Bax}+/+$ control $(C)$ and $G r i d 2^{L c /+} ; \mathrm{Bax}_{-} /-(D)$ double mutant mice.
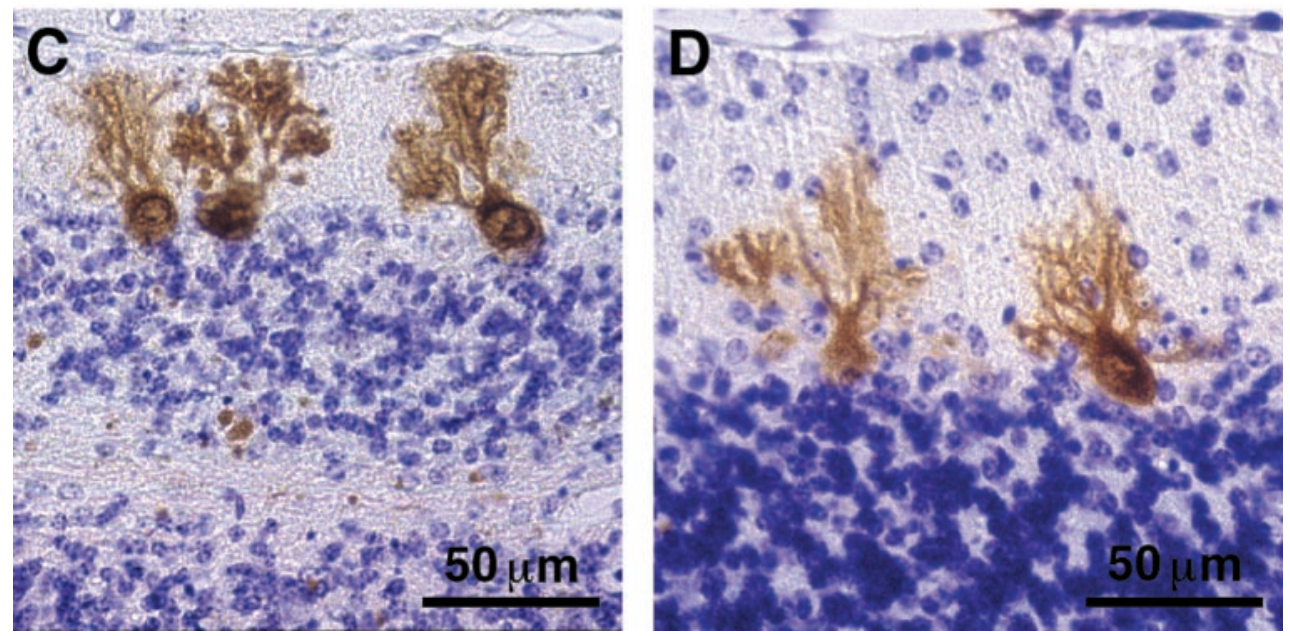

Bax exon 5 forward primer (5'GAGCTGATCAGAACCATCATG3'), Bax intron 5 reverse primer (5'GTTGACCAGAGTGGCGTAGG3'), and $\mathrm{Neo}$ reverse primer $\left(5^{\prime} \mathrm{CCGCTTCCATTGCTCAGCGG3').} \mathrm{Cycling} \mathrm{pa-}\right.$ rameters were $5 \mathrm{~min}$ at $94^{\circ} \mathrm{C}$ for one cycle, $1 \mathrm{~min}$ at $94^{\circ} \mathrm{C}, 1 \mathrm{~min}$ at $62^{\circ} \mathrm{C}$, and $1 \mathrm{~min} 30$ at $72^{\circ} \mathrm{C}$ for a total of 30 cycles. PCR products were resolved on a $1.5 \%$ agarose gel.

The Grid $2^{\mathrm{Lc}}$ allele was detected by PCR followed by single strand chain Polymorphism (SSCP) as described previously (Zuo et al., 1997). Briefly, $200 \mathrm{ng}$ of genomic DNA were used for a PCR with the two following primers: 5'TAAAAGCATATTGATGTTGTTG3' and 5'CAGCATTTGTCAGGTTTGGTGAC $3^{\prime}$. Cycling parameters were $2 \mathrm{~min}$ at $94^{\circ} \mathrm{C}$ for one cycle, $1 \mathrm{~min}$ at $94^{\circ} \mathrm{C}, 1 \mathrm{~min}$ at $60^{\circ} \mathrm{C}$, and $1 \mathrm{~min}$ at $72^{\circ} \mathrm{C}$ for a total of 30 cycles. PCR products were resolved by SSCP using GeneGel Excel 12.5/24 Kit (Amersham Pharmacia Biotech, Uppsala, Sweden) and revealed by silver staining of the gel.

Histology. Animals were anesthetized using $0.1 \mathrm{mg} / \mathrm{ml}$ chloral hydrate and perfused with $0.9 \%$ sodium chloride, followed by $95 \%$ ethanol. Brains were dissected, fixed overnight in Clarke's fixative, and processed for paraffin-embedding.

Parasagittal sections (10- $\mu$ m-thick) of the cerebellum were processed for calbindin immunohistochemistry. Sections were incubated overnight at $4^{\circ} \mathrm{C}$ with CL-300 monoclonal antibody (dilution, 1:200; Sigma, St. Louis MO). Immunocomplexes were revealed using a peroxidase-conjugated anti-mouse antibody (dilution, 1:500; Jackson ImmunoResearch, West Grove, PA) and diaminobenzidine tetrahydrochloride substrate (DAB Sigmafast; Sigma). Sections were then counterstained with cresyl violet-thionin.

Coronal sections (10- $\mu \mathrm{m}$-thick) of the brainstem were stained with cresyl violet-thionin to locate the inferior olive and analyze its morphology. Sections from 10 different rostrocaudal levels of the inferior olive were observed in each animal to compare the morphology of all the subnuclei of the olive.

Quantitative analysis. The total numbers of Purkinje cells and granule cells per half-cerebellum were counted in mutant and control cerebella. Cerebellar sections were stained for calbindin immunohistochemistry, and the number of calbindin-positive Purkinje cells was counted in each 40th section at $1000 \times$ magnification. The total number of Purkinje cells was calculated from a graph of the number of Purkinje cells in each counted section plotted against the distance of the section from the midline. Corrections were made for double counting Purkinje cells based on the method of Hendry (1976). We chose to use this traditional correction factor for our cell counts instead of more recently developed stereological techniques so that our results would be directly comparable with previously published counts. The total number of granule cells per half-cerebellum was estimated from the volume of the internal granule cell layer (IGL) multiplied by the average density of granule cells in the IGL. The granule cell density was estimated by counting at $1000 \times$ magnification the number of granule cells contained in an area of $25000 \mu \mathrm{m}^{3}$. These counts were done in six different regions in four sections from each half-cerebellum. Thus, the number of granule cells in 24 grids were counted to obtain the average density of granule cells. The volume of the IGL was calculated from a graph of granule cell layer area plotted against distance from the midline. The area of the IGL in each 40th section was measured using a CCD camera and NIH Image software. Corrections for double counting errors were made using the methods of Hendry (1976). Three to five animals of each genotype were used at each age: at P15, three animals of each genotype; at P30, four Grid2 $2^{L /+} ; B a x+/+$, four Grid2 $2^{L c /+} ; B a x+/-$, and five Grid2 ${ }^{L C /+} ;$ Bax $-1-$; at P60, three Grid2 ${ }^{L C /+} ;$ Bax $+/+$ and four Grid2 $2^{L c /+} ;$ Bax - /-. Statistical comparisons were made using ANOVA followed by Newman-Keuls post hoc test (significant when $p<0.05$ ).

\section{RESULTS}

\section{Bax deletion does not rescue the Lurcher phenotype}

Lurcher heterozygous (Grid2 $2^{L /+}$ ) mice were crossed with Bax knock-out $(B a x-/-)$ mice to determine whether Bax inactivation rescued the Lurcher phenotype. Lurcher homozygotes were never found in the litters, suggesting that Bax deletion does not rescue the Lurcher homozygotes and is not sufficient to inhibit the death of brainstem neurons in these animals. The Grid2 ${ }^{L c /+} ; B a x-/-$ mice were ataxic as the Grid $2^{L c /+} ; B a x+/+$ controls. However, the volume of their cerebellum was greater than that of $G r i d 2^{L c /+}$; $B a x+/+$ mice, suggesting that Bax deletion does rescue some of the cells normally degenerating in Lurcher mice.

\section{Bax deletion inhibits granule cell death in Lurcher mice}

Purkinje cell death in Grid2 $2^{L c /+}$ mice begins at approximately P8, and this neurodegeneration is accompanied by the loss of $90 \%$ of the granule cells. By P30, 90\% of Purkinje cells have already disappeared (Caddy and Biscoe, 1979), as well as $\sim 85 \%$ of granule cells (Doughty et al., 1999).

A qualitative observation of cerebellar sections taken from P30 animals showed that Bax deletion in Grid2 $2^{L c /+}$ mice inhibited granule cell but not Purkinje cell death. Immunohistochemistry using an anti-calbindin antibody to specifically stain Purkinje cells in the cerebellum showed that almost all Purkinje cells had degenerated in Grid2 $2^{L /+} ; B a x+/+$ controls (Fig. $1 A$ ) and $G r i d 2^{L c /+}$; Bax-/- double mutants (Fig. 1B) by P30. The morphology of 
Grid2 $2^{L c /+} ; B a x+/-$ cerebella (data not shown) was similar to Grid $2^{L c /+} ; B a x+/+$ cerebella. Only a few Purkinje cells remained in P30 animals of all three genotypes, primarily in one lobule of the cerebellum, the nodulus. The morphology of Purkinje cells in Grid $2^{L c /+} ;$ Bax $-/-$ double mutants (Fig. $1 D$ ) and $\mathrm{Grid}^{\mathrm{LCl+}}$; $B a x+1-$ cerebella was identical to the morphology of Purkinje cells in Grid $^{L c /+} ; B a x+/+$ control cerebellum (Fig. 1C). The dendrites of these cells were atrophic, thicker, and less branched than in normal mice as described previously (Dumesnil-Bousez and Sotelo, 1992; Doughty et al., 1999). Quantitative analysis of the number of Purkinje cells per hemi-cerebellum at P30 showed that there was no significant difference between the numbers of Purkinje cells found in Grid2 $2^{L c /+} ; B a x+/-(3208 \pm 723)$ and Grid $2^{L c /+} ; B a x+/+(3162 \pm$ 298) control mice. The number of Purkinje cells in $G r i d 2^{L c /+}$; Bax $-/-$ double mutants $(6364 \pm 520)$ was very low, confirming that Bax inactivation does not rescue Purkinje cells. However, this number was significantly higher than the number found in Grid2 $2^{L c /+} ; B a x+/-$ and Grid2 $2^{L c /+} ; B a x+/+$ mice, suggesting that Bax inactivation might delay Lurcher Purkinje cell death (see Fig. 4A).

Nuclear staining of the P30 sections using cresyl violet-thionin showed a clear increase of the area of the internal granule cell layer in double mutant cerebella when compared with $G r i d 2^{L c /+}$; Bax $+/+$ and Grid2 $2^{L c /+} ; B a x+/-$ control cerebella. The number of granule cells per hemi-cerebellum was significantly higher in Grid $2^{L c /+} ;$ Bax $-/-$ cerebella $\left(10.80 \pm 0.78 \times 10^{6}\right)$ compared with Grid2 $^{\text {Lc/+}} ;$ Bax $+1+\left(3.16 \pm 0.35 \times 10^{6}\right)$ and Grid2 ${ }^{L c /+} ;$ Bax $+/-$ $\left(2.87 \pm 0.13-10^{6}\right)$ cerebella (see Fig. 4B; ANOVA followed by post hoc Newman-Keuls test analysis, $p<0.01$ ), confirming that Bax inactivation in Grid2 $2^{L c /+}$ mice rescues granule cells. The number of granule cells per hemi-cerebellum of Frid $^{L c /+} ; B a x+/-$ animals was not statistically different from the number of granule cells found in $\mathrm{Grid}_{2}{ }^{L c /+} ; \mathrm{Bax}+/+$ animals, showing that inactivation of only one allele of Bax is not sufficient to inhibit cell death in Grid2 $2^{L c /+}$ mice.

Sixty to $75 \%$ of the inferior olivary neurons normally degenerate in Grid2 $2^{L c /+}$ mice following the death of their Purkinje cell targets (Caddy et al., 1979; Heckroth et al., 1991; Herrup et al., 1996). Fifty-four percent of these neurons have disappeared by P26 (Caddy and Biscoe, 1979). To determine whether Bax deletion was able to rescue the target-related cell death of olivary neurons in Lurcher mice, we analyzed the morphology of the inferior olive in P30 $G r i d 2^{L c /+} ; B a x-/-$ double mutant animals. Coronal sections of the brainstem from 10 different rostrocaudal levels of the inferior olive were stained with cresyl violet-thionin. No obvious difference was detected between the inferior olive of $\mathrm{Grid}^{\mathrm{Lc/+}} ; \mathrm{Bax}-/-$ double mutant and Grid2 ${ }^{L c /+} ; B a x+/+$ control mice (Fig. $2 B, C$ ). A massive loss of olivary neurons was observed in all the subnuclei of the inferior olive in both Grid $2^{L c /+} ; B a x-/-$ double mutants and $G r i d 2^{L c /+} ; B a x+/+$ control mice when compared with the inferior olive of a wild-type mouse (Fig. $2 A$ ). The rostrocaudal extension of the inferior olive was $\sim 1100 \mu \mathrm{m}$ in both Grid $2^{L c /+} ; B a x-/-$ double mutant and $G r i d 2^{L c /+} ; B a x+/+$ control mice. This value is reduced compared with the wild-type one in accordance with the results of Heckroth and Eisenman (1991). This result suggests that Bax inactivation does not inhibit the target-related cell death of inferior olivary neurons occurring in Grid2 $2^{L c /+}$ mice.

The results of the double Grid2 $2^{L c /+}$ and Bax-/- cross at P30 show that Bax inactivation in Lurcher mice inhibits target-related granule cell death but not the target-related death of inferior olivary neurons or intrinsic Purkinje cell death.

\section{Purkinje cell death is temporarily delayed by Bax inactivation in Lurcher mice}

Cerebellar sections from P15 mice were analyzed to look for an early effect of Bax inactivation on Lurcher Purkinje cell death. At P15, numerous Purkinje cells were still present in $\mathrm{Grid}_{2}{ }^{\mathrm{Cc} /+}$; Bax $+/+$ control and Grid $2^{L c /+} ; B a x-/-$ double mutant mice (Fig. 3 ). The presence of gaps in the Purkinje cell layer showed that Purkinje cell degeneration has already begun at this age in animals
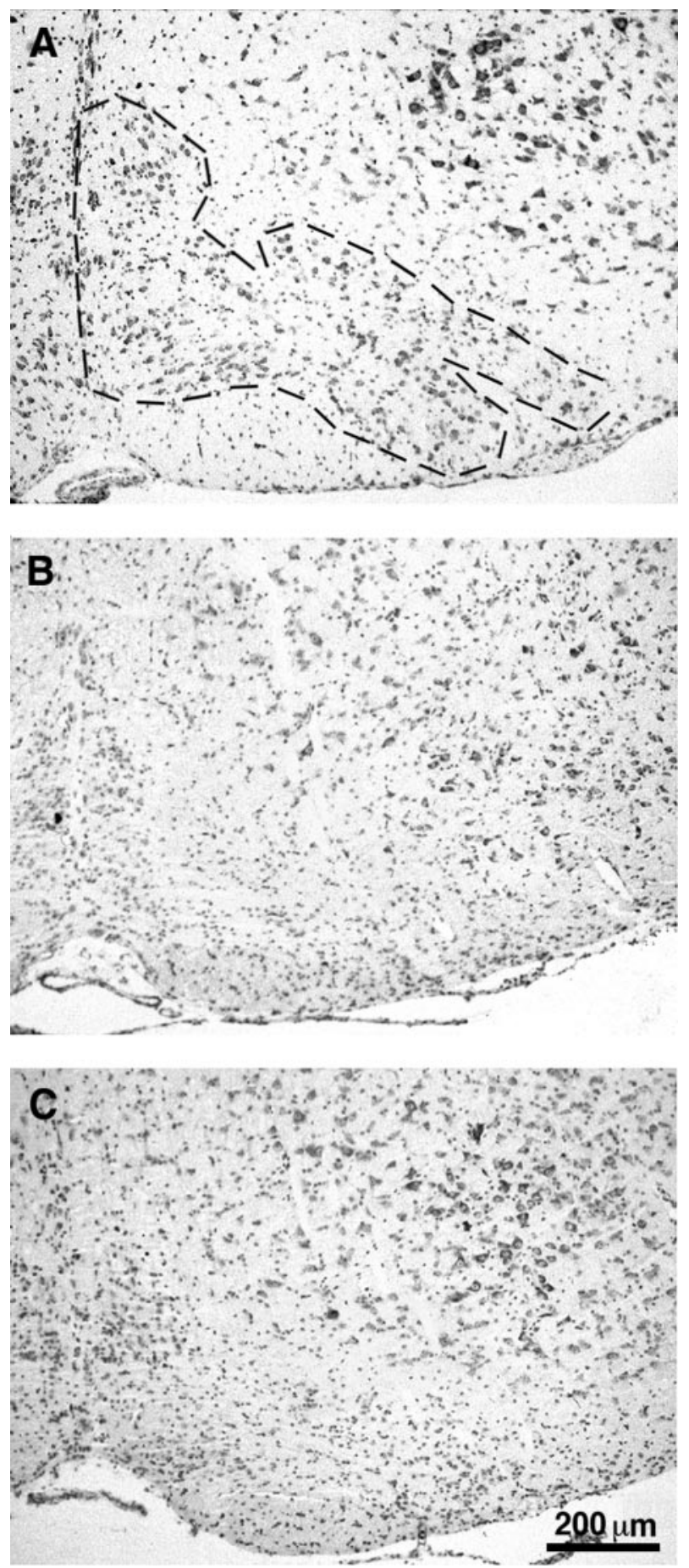

Figure 2. Neurodegeneration in the inferior olive of Lurcher mice is not inhibited by Bax inactivation. Coronal sections $(10-\mu \mathrm{m}$-thick) of the brainstem were stained using cresyl violet-thionin. Comparison of the inferior olive in wild-type mice $(A$, delineated by a dotted line) and Grid2 $2^{L c /+} ; B a x+/+(B)$ control mice shows a massive degeneration of neurons in the mutant. This neurodegeneration is also observed in $\mathrm{Grid}^{\mathrm{Lc} /+}$; Bax $-1-$ double mutants $(C)$ and makes the subnuclei of the inferior olive hardly recognizable in contrast to wild-type.

of both genotypes (Fig. $3 A, C$ ), in concordance with the observation that progressive neurodegeneration begins at approximately P8. Quantification of the Purkinje cell number per hemicerebellum (Fig. $4 A$ ) showed that their number was significantly higher in Grid2 ${ }^{L c /+} ;$ Bax $-/-$ double mutant cerebella (62,680 \pm 2152) compared with Grid2 ${ }^{L c /+} ;$ Bax $+/+$ cerebella $(45,261 \pm 1813$; ANOVA followed by post hoc Newman-Keuls test analysis, $p<$ $0.05)$. The analysis of the laterolateral distribution of Purkinje cells 

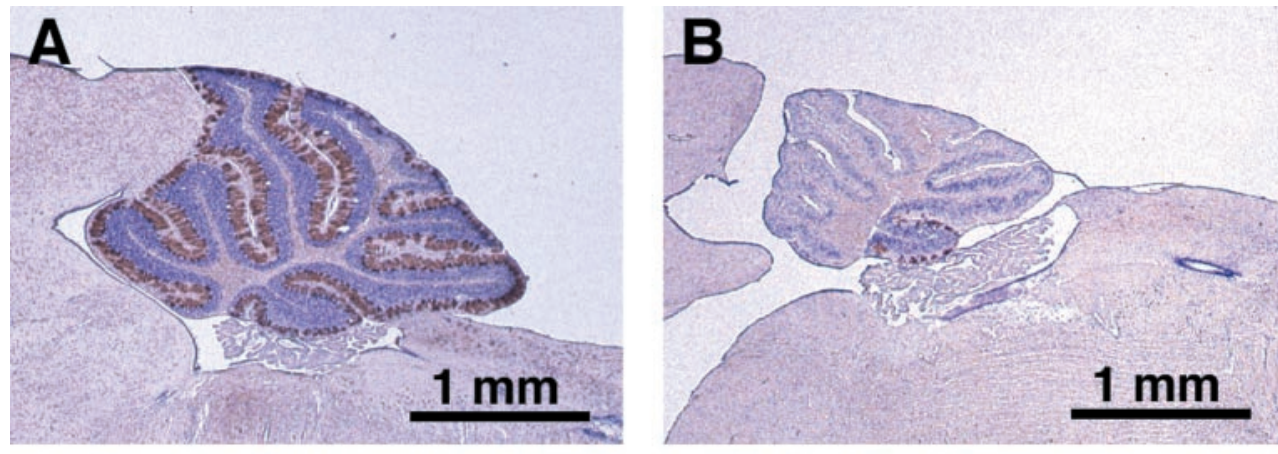

Figure 3. Morphology of the cerebellum of control Lurcher and Bax knock-out Lurcher mice at P15 and 2 months. Purkinje cell death has already begun at P15 from Grid2 $2^{L C /+} ; \operatorname{Bax}+/+$ controls $(A)$ as well as Grid $2^{L c /+} ;$ Bax $-/-$ double mutant mice $(C)$, as shown by the presence of gaps in the Purkinje cell layer. The surface of the internal granule cell layer is persistently increased at 2 months in Grid $2^{L C /+}$; Bax $-/-$ double mutant mice $(D)$ when compared with Grid2 $2^{L c /+} ; \mathrm{Bax}+/+$ control animals $(B)$.
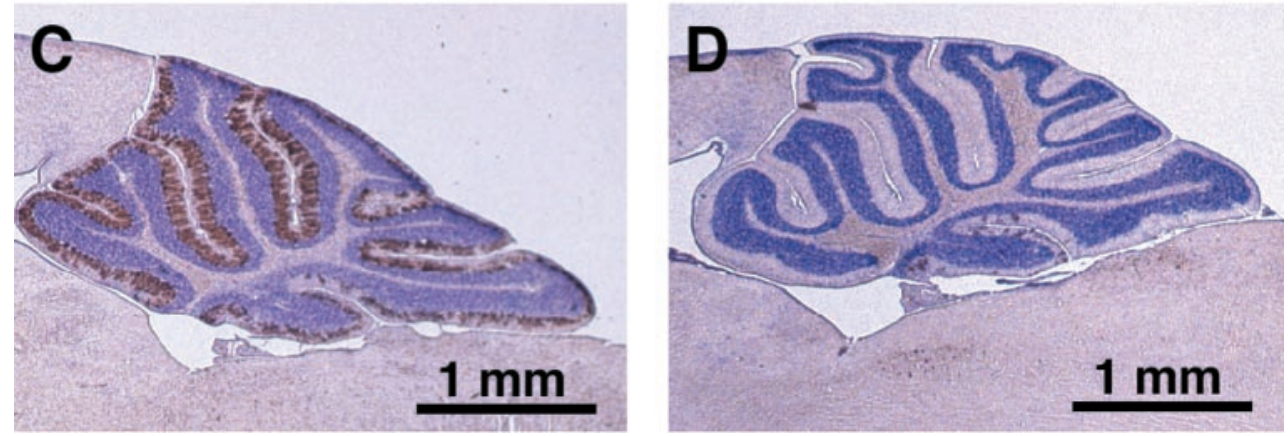

in both $\mathrm{Grid}_{2}{ }^{\mathrm{Lc} /+} ; \mathrm{Bax}-/-$ and $\mathrm{Grid}_{2}{ }^{\mathrm{Lc} /+} ; \mathrm{Bax}+/+$ cerebella showed that the number of Purkinje cells was increased throughout all the regions of the cerebellum in double mutants, indicating that Bax inactivation does not rescue a particular subpopulation of Purkinje cells (Fig. 4C). The number of granule cells in Grid $2^{L c /+} ; B a x-1-$ animals was already significantly higher than in Grid $^{L c /+} ;$ Bax $+/+$ mice $\left(9.09 \pm 0.38 \times 10^{6}\right.$ vs $6.50 \pm 0.06 \times 10^{6}$, respectively; ANOVA, followed by post hoc Newman-Keuls test analysis, $p<0.05)$ and was not significantly different from the one found in P30 animals (Fig. 4B).

These results show that $B a x$ inactivation does not inhibit but temporarily delays the degeneration of some Purkinje cells in Lurcher mice until P30.

\section{Granule cell rescue by Bax inactivation is persistent}

The effect of Bax inactivation in P60 animals was analyzed to determine whether granule cell rescue was a lasting effect in Grid $2^{L c /+}$ double mutants (Fig. $3 B, D$ ). In Grid2 $2^{L c /+} ; B a x+/+$ control mice as well as in Grid2 $2^{L c /+} ; B a x-/-$ double mutant mice, Purkinje cell degeneration was almost complete at this age, except for few cells still remaining in the nodulus $(525 \pm 97$ vs $1268 \pm 218$, respectively; ANOVA followed by post hoc Newman-Keuls test analysis, $p>0.05$ ) (Fig. $4 A$ ). The number of granule cells per $\mathrm{Grid}^{L c /+} ; \mathrm{Bax}+/+$ half-cerebellum was $1.39 \pm 0.06 \times 10^{6}, \sim 10 \%$ of the normal number of granule cells. Thus, the degeneration of granule cells is almost complete at this age in Grid2 ${ }^{L c /+} ; B a x+/+$ control mice as $10 \%$ of these cells still remain at P730 (Caddy and Biscoe, 1979). The analysis of cerebellar sections from P60 Grid $2^{L c /+} ;$ Bax $-/-$ double mutant mice (Fig. $3 D$ ) revealed that the area of the internal granule cell layer was still increased when compared with Grid2 ${ }^{L c /+} ; B a x+/+$ control mice (Fig. $3 B$ ). The number of granule cells per hemi-cerebellum in Grid2 ${ }^{L c /+} ; B a x-/-$ mice $\left(11.05 \pm 0.41 \times 10^{6}\right)$ was significantly higher compared with Grid2 ${ }^{L c /+} ; B a x+/+$ controls (ANOVA followed by the NewmanKeuls post hoc test analysis, $p<0.05)$. This number was not significantly different from the numbers of granule cells found in Grid2 $^{L c /+} ; B a x-/-$ mice at P15 and P30 (ANOVA followed by the Newman-Keuls post hoc test analysis, $p>0.05)$. The number of rescued granule cells is $\sim 70 \%$ of the number of granule cells found in wild-type animals (Vogel et al., 1991). These results indicate that granule cell rescue by Bax inactivation in Lurcher is persistent until at least 2 months.

\section{DISCUSSION}

The Lurcher mutant presents a unique opportunity to study two distinct neuronal cell death mechanisms in the same in vivo model in which the primary cause of Purkinje cell death has been identified as a gain of function mutation in a glutamate receptor channel and the secondary cause of granule and olivary neuron cell death is loss of target trophic support. In this study, we show that deletion of Bax expression in the Grid2 ${ }^{L c /+}$ mutant does not prevent Purkinje cell or olivary neuron cell death, but it does rescue granule cells.

\section{Purkinje cell death in the Grid2 ${ }^{L c /+}$ mutant}

All but a few cerebellar Purkinje cells, $90 \%$ of the granule cells, and $60-75 \%$ of the olivary neurons degenerate postnatally in the Grid2 ${ }^{L C /+}$ mutant (Phillips, 1960; Caddy and Biscoe, 1979). Whereas Grid2 ${ }^{L c /+}$ PC loss is attributable to a cell autonomous genetic defect involving a gain of function mutation in the $\delta 2$ glutamate receptor (Grid2) (Zuo et al., 1997), the mechanisms of PC death in the Grid2 $2^{L C /+}$ mutant have not yet been definitively characterized. Grid2 $2^{L c /+}$ PC death has been described as necrotic based on morphological criteria (Dumesnil-Bousez and Sotelo, 1992). However, dying Grid2 $2^{L c /+}$ PCs have been labeled with TUNEL and contain increased levels of apoptosis-related proteins, such as BAX, BCL-x, and both pro-caspase-3 and activated caspase-3, suggesting an apoptotic mechanism (Norman et al., 1995; Wullner et al., 1995, 1998; Selimi et al., 2000).

The involvement of apoptosis-related proteins in Grid2 ${ }^{L c /+}$ Purkinje cell death is also shown by the ability of $b c l-2$ transgene overexpression to delay Grid2 $2^{L c /+}$ PC death (Zanjani et al., $1998 \mathrm{a}, \mathrm{b})$. One of the mechanisms by which BCL-2 may exert its neuroprotective action is through inhibition of the pro-apoptotic protein BAX (Oltvai et al., 1993; Antonsson et al., 1997; Mahajan, 1998). BAX mRNA is expressed at high levels in the postnatal mouse brain (De Bilbao et al., 1999). BAX protein expression levels may gradually decline in the cerebellum through the first $21 \mathrm{~d}$ of development, although expression levels of BAX remain high in PCs in the adult (Vekrellis et al., 1997). BAX plays an important role in naturally occurring cell death because neuronal cell death is reduced in $\mathrm{Bax}-1-$ mice; for example, the number of facial nucleus motoneurons is increased by $51 \%$ (Deckwerth et al., 1996; White et al., 1998). 


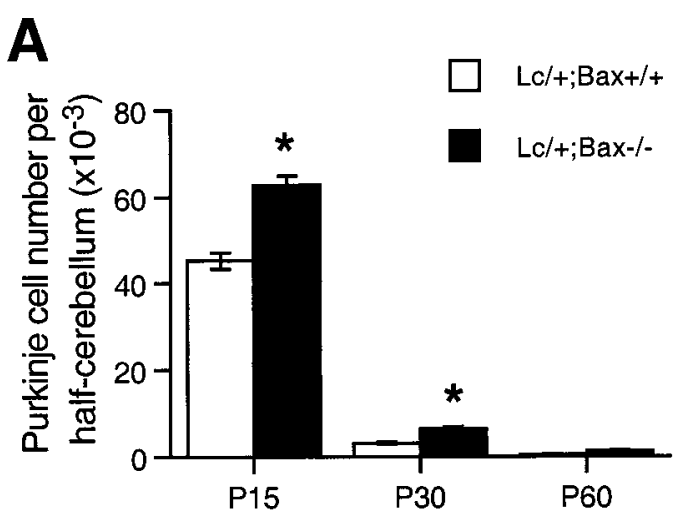

B

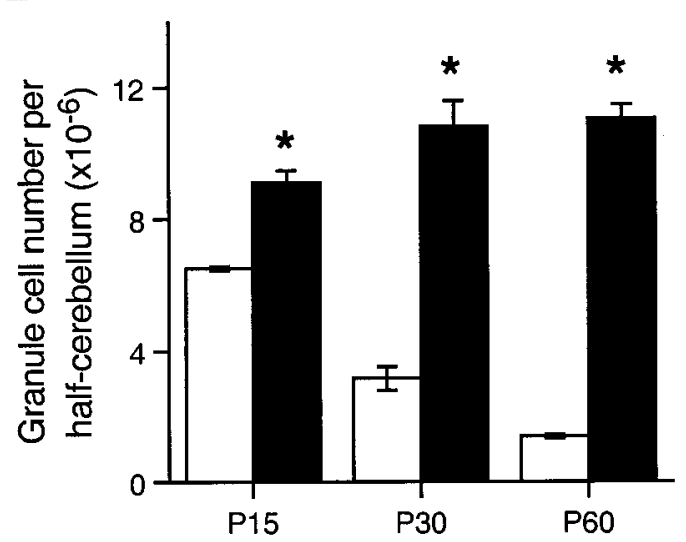

C

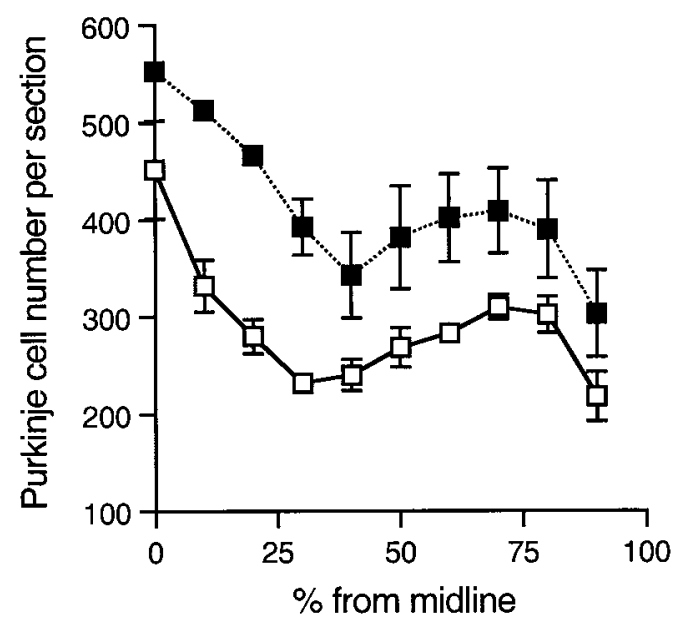

Figure 4. Quantitative analysis of neuronal death in the cerebellum of Bax knock-out Lurcher mice. $A$, Purkinje cell number per half-cerebellum was assessed using anti-calbindin immunostained cerebellar sections. $B$, Granule cell number per half-cerebellum was estimated multiplying the area of the internal granule cell layer by the average density of granule cells. Asterisks indicate that numbers found in Grid2 $2^{\mathrm{L} /+} ; \mathrm{Bax}-1-$ double mutant mice are statistically different from numbers found in $G r i d 2^{L c /+} ; \mathrm{Bax}+/+$ mice $(p<0.05$, ANOVA followed by post hoc Newman-Keuls test analysis). Error bars indicate SEM $(n=3-5)$. $C$, Averaged laterolateral distribution of the Purkinje cell population in P15 aged mutants of both genotypes. The mean Purkinje cell counts per homologous parasagittal section are plotted against the distance from the midline (percentage). Cell numbers in Grid $2^{\mathrm{Lc} /+} ; \mathrm{Bax}-/-$ double mutants are significantly higher than in Grid $2^{L c /+} ; \mathrm{Bax}+/+$ mice without any effect of the laterolateral position (two-factor ANOVA). Each point represents mean \pm SEM (for some points, the error bar is smaller than the dot).
BAX expression is increased in dying Grid2 $2^{L c /+}$ PCs, suggesting it may play a role in their death (Wullner et al., 1998). Yet, it is surprising that deletion of BAX expression only slightly delays Grid $2^{L c /+}$ PC death. The number of Grid2 $2^{L c /+}$ Purkinje cells is significantly increased at P15 in the Grid $2^{L c /+}$ double mutant, but by P30 this number has returned to a low level, and at P60 is not significantly different to the one found in the Grid $2^{L c /+}$ mutant. The available evidence suggests that Grid $2^{L c /+}$ PCs may die by an excitotoxic mechanism induced by the accumulation of leaky GRID2 subunits at developing PC-parallel fiber synapses (Zuo et al., 1997; De Jager and Heintz, 1998). The Lurcher gain of function mutation in Grid2 results in a large, constitutive inward sodium current in the cells that express the subunit and might induce a defect in $\mathrm{Ca}^{2+}$ homeostasis (Zuo et al., 1997). Although we cannot rule out a role for BAX-induced apoptosis in Grid2 ${ }^{L c l+} \mathrm{PCs}$, their death in Bax knock-out Lurcher mutants indicates that BAX is not necessary for their demise. One likely hypothesis is that there are multiple pathways and/or other BCL-2 family members capable of inducing cell death in stressed cells, including Purkinje cells. The slight delay in Grid $2^{L c /+} \mathrm{PC}$ death seen at P15 may represent the difference between BAX cell death usually induced in Grid2 ${ }^{L c /+}$ mutants and a different mechanism induced in $\mathrm{Grid}^{\mathrm{Lc} /+} ; \mathrm{Bax}-1-$ double mutants. BCL-2 overexpression may be able to temporarily rescue Grid2 ${ }^{L c /+}$ Purkinje cells (Zanjani et al., 1998a) because of its ability to bind to BAX and prevent the formation of BAX channels (Antonsson et al., 1997; Mahajan, 1998) and/or its ability to regulate intracellular $\mathrm{Ca}^{2+}$ homeostasis (Murphy et al., 1996; Ichimiya et al., 1998; Kuo et al., 1998). However, in the end, the $G r i d 2^{L c /+}$ mutation is lethal and neither Bax inactivation or bcl-2 overexpression can rescue Lurcher Purkinje cells.

\section{Granule cell survival and olivary neuron death}

In the olivocerebellar system, surgical and genetic lesions have shown that the survival of olivary neurons and granule cells is dependent on interactions with their PC targets (Harkmark, 1956; Sotelo and Changeux, 1974; Caddy and Biscoe, 1979; Wetts and Herrup, 1982a,b; Zanjani et al., 1990; Vogel et al., 1991; Herrup et al., 1996). Many olivary neurons and granule cells undergo apoptotic cell death when deprived of their target (Chu and Oberdick, 1995; Smeyne et al., 1995). In the Grid $2^{L c /+}$ mutant, activated caspase-3 is found in dying granule cells and olivary neurons (Selimi et al., 2000). There are multiple lines of evidence that support a role for BCL-2-related proteins, including BAX, in target-related cell death. We have shown previously that overexpression of $b c l-2$ in $G r i d 2^{L c /+}$ olivary neurons will rescue most of the olivary neurons from target-related cell death (Zanjani et al., 1998b). This result is consistent with previous studies showing in vitro rescue of neurons from trophic factor withdrawal (Garcia et al., 1992; Allsopp et al., 1993; Batistatou et al., 1993) and in vivo rescue of neurons from axotomy or ischemia by $b c l-2$ overexpression (Dubois-Dauphin et al., 1994; Martinou et al., 1994; Farlie et al., 1995; Bonfanti et al., 1996; De Bilbao and Dubois-Dauphin, 1996) or deletion of Bax expression (Deckwerth et al., 1996; White et al., 1998).

However, our results reveal differences in the pathway leading to this target-related cell death in vivo; deletion of Bax expression in Grid2 ${ }^{L C+}$ mutants rescues granule cells but does not prevent olivary neuron death. Both populations are dying because of loss of their target, but granule cell death appears to be dependent on Bax expression, whereas olivary neuron cell death can be independent of Bax. Granule cell rescue could have been a consequence of the delay in Purkinje cell death. For example, in $p c d$ mutant mice, Purkinje cell death occurs between the third and sixth postnatal week, and the number of granule cells is not different from controls in P30 animals. However, this number is significantly decreased in 3-month-old pcd mutants and follows an exponential decay, suggesting that a transient trophic support from Purkinje cells is not sufficient to inhibit persistently target-related granule cell death (Triarhou, 1998). Not even a slight decrease in granule cell numbers was observed in Bax knock-out Lurcher mice from P15 to P60, 
suggesting that the delay in Purkinje cell death is unlikely to be the only cause of granule cell rescue. Our estimates of granule cell numbers indicate that there is an eightfold increase in the number of surviving granule cells in the Grid $2^{L c /+} ; B a x-/-$ double mutants compared with Grid2 ${ }^{L c /+} ; B a x+/+$ controls. Granule cell numbers in our Bax knock-out Lurcher mutants are only reduced by $30 \%$ compared with wild-type numbers (Vogel et al., 1991). The number of granule cells in $\mathrm{Grid}_{2}{ }^{L c /+} ; \mathrm{Bax}-/-$ double mutants is comparable with the maximum of granule cells detected in $G r i d 2^{L c /+}$; Bax $+/+$ cerebella $\left(8 \times 10^{6}\right)($ Caddy and Biscoe, 1979). Thus, Bax inactivation does not significantly affect the deficit in granule cell genesis detected in Lurcher mutants. It seems more likely that the primary cause of granule cell rescue in Bax knock-out Lurcher mice is the loss of Bax expression. Wild-type and Lurcher granule cells have been shown to express Bax during the period of degeneration in Lurcher cerebellum (Vekrellis et al., 1997; Wullner et al., 1998), and our results suggest that Bax plays an important role in regulating granule cell death after removal of target-related trophic support.

The molecular pathways that link trophic factor deprivation with cell death have not yet been fully characterized. The binding of trophic factors with their receptors triggers a variety of signaling responses that promote cell survival, in some cases through interactions with BCL-2-related proteins (Kaplan and Miller, 1997; Pettmann and Henderson, 1998). For example, NGF or IGF-1 can induce the phosphorylation of $\mathrm{BAD}$, a non-membrane-bound BCL-2 relative, by activating Akt, a serine-threonine protein kinase. In the absence of trophic factor, nonphosphorylated BAD will bind to Bcl-x and prevent the anti-apoptotic activity of BCL-X. The anti-apoptotic activity of BCL-x may involve binding to BAX to prevent it from opening a pore in mitochondrial membranes (Gross et al., 1999). Recently, NGF has also been shown to promote Bcl-2 expression in NGF-responsive neurons (Riccio et al., 1999). It is yet not clear what pathway or pathways are involved in cell death in granule cells and olivary neurons. There are a large variety of BCL-2-related cell death proteins that promote or block cell death (Gross et al., 1999). For example, the loss of Bax expression in $\mathrm{Bcl}-\mathrm{x}$ deficient mice prevents most, but not all, cell death so there must be other cell death-promoting proteins (Shindler et al., 1997). The rescue of granule cells, but not olivary neurons, by Bax inactivation after target loss indicates that, although BAX is required for target-related cell death in granule cells, there may be other cell death-promoting proteins functioning in olivary neurons.

\section{REFERENCES}

Adams JM, Cory S (1998) The bcl-2 protein family: arbiters of cell survival. Science 281:1322-1326.

Allsopp TE, Wyatt S, Paterson HF, Davies AM (1993) The protooncogene bcl-2 can selectively rescue neurotrophic factor-dependent neurons from apoptosis. Cell 73:295-307.

Antonsson B, Conti F, Ciavatta A, Montessuit S, Lewis S, Martinou I Bernasconi L, Bernard A, Mermod JJ, Mazzei G, Maundrell K, Gambale F, Sadoul R, Martinou JC (1997) Inhibition of Bax channel-forming activity by Bcl-2. Science 277:370-372.

Batistatou A, Merry DE, Korsmeyer SJ, Greene LA (1993) Bcl-2 affects survival but not neuronal differentiation of PC12 cells. J Neurosci 13:4422-4428.

Bonfanti L, Strettoi E, Chierzi S, Cenni MC, Liu X-H, Martinou J-C, Maffei L, Rabacchi SA (1996) Protection of retinal ganglion cells from natural and axotomy-induced cell death in neonatal transgenic mice overexpressing bcl-2. J Neurosci 16:4186-4194.

Caddy KWT, Biscoe TJ (1979) Structural and quantitative studies on the normal $\mathrm{C} 3 \mathrm{H}$ and Lurcher mutant mouse. Phil Trans R Soc Lond B Biol Sci 287:167-201.

Chu T, Oberdick J (1995) An early critical period in olivocerebellar interactions defined by targeted ablation of Purkinje cells. Soc Neurosci Abstr 21:916.

De Bilbao F, Dubois-Dauphin M (1996) Time course of axotomy-induced apoptotic cell death in facial motoneurons of neonatal wild type and bcl-2 transgenic mice. Neuroscience 71:1111-1119.

De Bilbao F, Guarin E, Nef P, Vallet P, Giannakopoulos P, DuboisDauphin M (1999) Postnatal distribution of cpp32/caspase 3 mRNA in the mouse central nervous system: an in situ hybridization study. J Comp Neurol 409:339-357.

De Jager PL, Heintz N (1998) The lurcher mutation and ionotropic glutamate receptors: contributions to programmed neuronal death in vivo. Brain Pathol 8:795-807.

Deckwerth TL, Elliott JL, Knudson CM, Johnson EMJ, Snider WD, Korsmeyer SJ (1996) BAX is required for neuronal death after trophic factor deprivation and during development. Neuron 17:401-411.

Doughty ML, Lohof A, Selimi F, Delhaye-Bouchaud N, Mariani J (1999) Afferent-target cell interactions in the cerebellum: negative effect of granule cells on Purkinje cell development in Lurcher mice. J Neurosci 19:3448-3456.

Dubois-Dauphin M, Frankowski H, Tsujimoto Y, Huarte J, Martinou J-C (1994) Neonatal motoneurons overexpressing the bcl-2 protooncogene in transgenic mice are protected from axotomy-induced cell death. Proc Natl Acad Sci USA 91:3309-3313.

Dumesnil-Bousez N, Sotelo C (1992) Early development of the Lurcher cerebellum: Purkinje cell alterations and impairment of synaptogenesis. J Neurocytol 21:506-529.

Farlie PG, Dringen R, Rees SM, Kannourakis G, Bernard O (1995) bcl-2 transgene expression can protect neurons against developmental and induced cell death. Proc Natl Acad Sci USA 92:4397-4401.

Garcia I, Martinou I, Tsujimoto Y, Martinou JC (1992) Prevention of programmed cell death of sympathetic neurons by the bcl-2 protooncogene. Science 258:302-304.

Gross A, McDonnell JM, Korsmeyer SJ (1999) BCL-2 family members and the mitochondria in apoptosis. Genes Dev 13:1899-1911.

Harkmark W (1956) The influence of the cerebellum on development and maintenance of the inferior olive and the pons. J Exp Zool 131:333-372.

Heckroth JA, Eisenman LM (1991) Olivary morphology and olivocerebellar topography in adult lurcher mutant mice. J Comp Neurol 312:641-651.

Hendry IA (1976) A method to correct adequately for the change in neuronal size when estimating neuronal numbers after nerve growth factor treatment. J Neurocytol 5:337-349.

Herrup K, Shojaeian-Zanjani H, Panzini L, Sunter K, Mariani J (1996) The numerical matching of source and target populations in the CNS: the inferior olive to Purkinje cell projection. Dev Brain Res 96:28-35.

Ichimiya M, Chang SH, Liu H, Berezesky IK, Trump BF, Amstad PA (1998) Effect of Bcl-2 on oxidant-induced cell death and intracellular $\mathrm{Ca}^{2+}$ mobilization. Am J Physiol 275:C832-C839.

Kaplan DR, Miller FD (1997) Signal transduction by the neurotrophin receptors. Curr Opin Cell Biol 9:213-221.

Knudson CM, Tung KSK, Tourtelotte WG, Brown AJ, Korsmeyer SJ (1995) Bax-deficient mice with lymphoid hyperplasia and male germ cell death. Science 270:96-99.

Kuo TH, Kim HR, Zhu L, Yu Y, Lin HM, Tsang W (1998) Modulation of endoplasmic reticulum calcium pump by Bcl-2. Oncogene 17:1903-1910.

Mahajan (1998) Bcl-2 and Bax interactions in mitochondria probed with green fluorescent protein and fluorescence resonance energy transfer. Nat Biotech 16:547-552.

Martinou J-C, Dubois-Dauphin M, Staple J, Rodriguez I, Frankowski H, Missotten M, Albertini P, Talabot D, Catsicas S, Pietra C, Huarte J (1994) Overexpression of BCL-2 in transgenic mice protects neurons from naturally occurring cell death and experimental ischemia. Neuron 13:1017-1030.

Murphy AN, Bredesen DE, Cortopassi G, Wang E, Fiskum G (1996) Bcl-2 potentiates the maximal calcium uptake capacity of neural cell mitochondria. Proc Natl Acad Sci USA 93:9893-9898.

Norman D, Feng L, Gubbay J, Chan E, Heintz N (1995) The lurcher gene induces apoptotic death in cerebellar Purkinje cells. Development 121:1183-1193.

Oltvai ZN, Milliman CL, Korsmeyer SJ (1993) Bcl-2 heterodimerizes in vivo with a conserved homolog, Bax, that accelerates programmed cell death. Cell 74:609-619.

Pettmann B, Henderson CE (1998) Neuronal cell death. Neuron 20:633-647.

Phillips RJS (1960) "Lurcher," a new gene in linkage group XI of the house mouse. J Genet 57:35-42.

Riccio A, Ahn S, Davenport CM, Blendy JA, Ginty DD (1999) Mediation by a CREB family transcription factor of NGF-dependent survival of sympathetic neurons. Science 286:2358-2361.

Selimi F, Doughty M, Delhaye-Bouchaud N, Mariani J (2000) Targetrelated and intrinsic neuronal death in Lurcher mutant mice are both mediated by caspase-3 activation. J Neurosci 20:992-1000.

Shindler KS, Latham CB, Roth KA (1997) Bax deficiency prevents the increased cell death of immature neurons in bcl-x-deficient mice. J Neurosci 17:3112-3119.

Smeyne RJ, Chu T, Lewin A, Bian F, Crisman SS, Kunsch C, Lira SA, Oberdick J (1995) Local control of granule cell generation by cerebellar Purkinje cells. Mech Cell Neurosci 6:230-251.

Sotelo C, Changeux J-P (1974) Transsynaptic degeneration "en cascade" in the cerebellar cortex of staggerer mutant mice. Brain Res 67:519-526.

Triarhou LC (1998) Rate of neuronal fallout in a transsynaptic cerebellar model. Brain Res Bull 47:219-222.

Vekrellis K, McCarthy MJ, Watson A, Whitfield J, Rubin LL, Ham J 
(1997) Bax promotes neuronal cell death and is downregulated during the development of the nervous system. Development 124:1239-1249.

Vogel MW, McInnes M, Zanjani HS, Herrup K (1991) Cerebellar Purkinje cells provide target support over a limited spatial range: evidence from lurcher chimeric mice. Dev Brain Res 64:87-94.

Wetts R, Herrup K (1982a) Interaction of granule, Purkinje and inferiorolivary neurons in lurcher chimeric mice. I. Qualitative studies. J Embryol Exp Morphol 68:87-98.

Wetts R, Herrup K (1982b) Interaction of granule, Purkinje and inferior olivary neurons in lurcher chimeric mice. II. Granule cell death. Brain Res 250:358-363.

White FA, Keller-Peck CR, Knudson M, Korsmeyer SJ, Snider WD (1998) Widespread elimination of naturally occurring neuronal death in Baxdeficient mice. J Neurosci 18:1428-1439.

Wullner U, Loschmann P-A, Weller M, Klockgether T (1995) Apoptotic cell death in the cerebellum of mutant weaver and lurcher mice. Neurosci Lett 200:109-112.
Wullner U, Weller M, Schulz J, Krajewski S, Reed J, Klockgether T (1998) $\mathrm{Bcl}-2$, Bax and Bcl-x expression in neuronal apoptosis: a study of mutant weaver and lurcher mice. Acta Neuropathol (Berl) 96:233-238.

Zanjani HS, Mariani J, Herrup K (1990) Cell loss in the inferior olive of the staggerer mutant mouse is an indirect effect of the gene. J Neurogenet 6:229-241.

Zanjani HS, Rondi-Reig L, Vogel MW, Martinou JC, Delhaye-Bouchaud $\mathrm{N}$, Mariani J (1998a) Overexpression of a $\mathrm{Hu}-\mathrm{Bcl}-2$ gene in Lurcher mutant mice delays Purkinje cell death. C R Acad Sci III 321:633-640.

Zanjani HS, Vogel MW, Martinou JC, Delhaye-Bouchaud N, Mariani J (1998b) Postnatal expression of $\mathrm{Hu}-\mathrm{Bcl}-2$ gene in Lurcher mutant mice fails to rescue Purkinje cells, but protects inferior olivary neurons from target related cell death. J Neurosci 18:319-327.

Zuo J, De Jager PL, Takahashi KA, Jiang W, Linden DJ, Heintz N (1997) Neurodegeneration in Lurcher mice caused by mutation in $\delta 2$ glutamate receptor. Nature 388:769-773. 